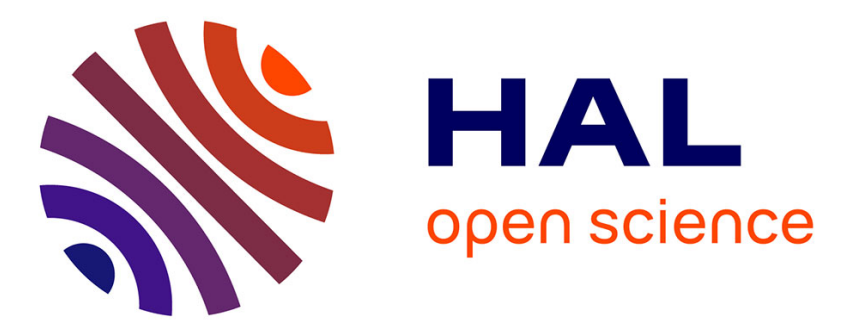

\title{
Subliminal display of action words interferes with motor planning: a combined EEG and kinematic study.
} Véronique Boulenger, Beata y Silber, Alice C Roy, Yves Paulignan, Marc Jeannerod, Tatjana A Nazir

\section{- To cite this version:}

Véronique Boulenger, Beata y Silber, Alice C Roy, Yves Paulignan, Marc Jeannerod, et al.. Subliminal display of action words interferes with motor planning: a combined EEG and kinematic study.. Journal of Physiology - Paris, 2008, 102 (1-3), pp.130-6. 10.1016/j.jphysparis.2008.03.015 . hal-00363141

\section{HAL Id: hal-00363141 https://hal.science/hal-00363141}

Submitted on 20 Feb 2009

HAL is a multi-disciplinary open access archive for the deposit and dissemination of scientific research documents, whether they are published or not. The documents may come from teaching and research institutions in France or abroad, or from public or private research centers.
L'archive ouverte pluridisciplinaire HAL, est destinée au dépôt et à la diffusion de documents scientifiques de niveau recherche, publiés ou non, émanant des établissements d'enseignement et de recherche français ou étrangers, des laboratoires publics ou privés. 


\title{
Subliminal display of action words interferes with motor planning: a combined EEG
} and kinematic study

Véronique Boulenger, Beata Y. Silber, Alice C. Roy, Yves Paulignan, Marc Jeannerod and Tatjana A. Nazir

\section{L2C2-Institut des Sciences Cognitives, UMR 5230 CNRS/Université Claude Bernard Lyon I,}

\author{
Bron, France
}

\begin{abstract}
Recent evidence has shown that processing action-related language and motor action share common neural representations to a point that the two processes can interfere when performed concurrently. To support the assumption that language-induced motor activity contributes to action word understanding, the present study aimed at ruling out that this activity results from mental imagery of the movements depicted by the words. For this purpose, we examined cross-talk between action word processing and an arm reaching movement, using words that were presented too fast to be consciously perceived (subliminally). Encephalogram (EEG) and movement kinematics were recorded. EEG recordings of the "Readiness Potential" ("RP", indicator of motor preparation) revealed that subliminal displays of action verbs during movement preparation reduced the RP and affected the subsequent reaching movement. The finding that motor processes were modulated by language processes despite the fact that words were not consciously perceived, suggests that cortical structures that serve the preparation and execution of motor actions are indeed part of the (action) language processing network.
\end{abstract}

Key-words: Action words - Motor preparation - Readiness Potential - Language processes Interference - EEG - Kinematics

\section{Corresponding Authors:}

Drs Véronique Boulenger \& Tatjana A. Nazir

L2C2-Institut des Sciences Cognitives

UMR 5230 CNRS/UCBL

67 boulevard Pinel

69675 Bron Cedex, France

boulenger@isc.cnrs.fr; nazir@isc.cnrs.fr 


\section{Introduction}

A recently emerging view considers that language processing and motor action share common neural substrates. Two major models, the first based on Hebbian learning (Pulvermüller, 1996, 2001, 2005) and the second on the existence of the "mirror neuron system" (Fadiga \& Craighero, 2004; Gallese \& Lakoff, 2005; Rizzolatti \& Arbib, 1998; Rizzolatti et al., 2001), suggest that processing of action words relies on activation of the motor programs used to perform, observe or simulate the actions referred to by words, either because of correlation learning (Pulvermüller, 2005) or because of a predisposition for imitation learning (Rizzolatti \& Arbib, 1998). Evidence for such shared representations between word processing and sensory-motor information is provided by a large range of empirical data (Aziz-Zadeh et al., 2006; Boulenger et al., 2006; Boulenger et al., in press; Buccino et al., 2005; Glenberg \& Kaschack, 2002; Glover et al., 2004; Hauk et al., 2004; Nazir et al., in press; Oliveri et al., 2004; Pulvermüller et al., 2005ab; Tettamanti et al., 2005; Zwaan \& Taylor, 2006; see Fischer \& Zwaan, in press, for a recent review). fMRI studies, for instance, have demonstrated somatotopic activation of motor and premotor cortices during processing of words or sentences referring to actions performed with arm, face or leg (AzizZadeh et al., 2006; Hauk et al., 2004; Tettamanti et al., 2005). Transcranial magnetic stimulation (TMS) studies have also revealed that the left motor cortex excitability changes during processing of words or sentences denoting bodily actions (Buccino et al., 2005; Oliveri et al., 2004).

First attempts to identify the functional role of language-related activity in cortical motor regions have also been made by investigating the time course of this activity (Boulenger et al., 2006; Pulvermüller et al., 2005a). Using magnetoencephalography (MEG), Pulvermüller et al. (2005a) revealed a short-lived somatotopic activity in motor cortex while participants were listening to face- and leg-related action words. This activity was observed within 170 to 200 ms post word onset, which is the time-window within which early lexico-semantic effects typically occur (Hauk et al., 2006; Pulvermüller et al., 1999a; Preissl et al., 1995; Sereno et al., 1998; Sereno \& Rayner, 2003). Given this critical delay, the authors suggested that cortical motor regions could be involved in action word retrieval and may thus be essential to (action) language understanding (for a summary of this idea, see Pulvermüller, 2005). Boulenger et al. (2006) corroborated this finding by showing cross-talk between action word processing and overt motor performance within the same early time-window. Fine-grained analyses of 
movement kinematics could in fact reveal that relative to nouns without specific motor associations, processing action verbs altered the kinematics of arm reaching movements. When the two tasks were performed concurrently, processing of action verbs interfered with the movement (i.e. it delayed and decreased wrist acceleration peak within $200 \mathrm{~ms}$ following onset), whereas facilitation of motor performance was observed when the words were processed prior to movement onset (i.e. it shortened time to wrist acceleration peak). By providing unambiguous evidence for the existence of behavioral correlates to languagerelated activity in motor regions, this latter study demonstrated that processing of action verbs and motor action share common neural representations to the point that the two processes can interfere with each other.

\section{The present study}

Despite these intriguing findings, a major argument against the assumption that cortical motor regions are involved in (action) word processing is that, even though language-induced activity in motor regions is observed within less than $200 \mathrm{~ms}$ after word onset, this activity could nonetheless result from mental motor imagery (voluntary or involuntary mental representation of the movements depicted by the words; see Jeannerod, 1994) that occurs after the word has been identified. If so, cortical motor regions would not be vital for the effective processing of action words and language-related cortical motor activity should rather be considered a by-product of language processing with no specific functional relevance. The aim of the present study is to rule out this possibility, by investigating cross-talk between language and motor processes using visual words that are masked by other visual symbols, and presented too fast to be consciously perceived: Words that are not consciously perceived can actually not trigger mental motor imagery.

Brain imaging studies have established that although participants do not consciously perceive a visually masked word, the subliminal stimulus automatically pre-activates essential parts of the cerebral networks for word processing (Dehaene et al., 2001) and boosts recognition when the same word is displayed again shortly afterwards (c.f. masked priming; Forster \& Davis, 1984; Forster, 1999; also see Marcel, 1983). If cortical motor regions are essential to the processing of action-related language, masked words that describe motor actions should therefore activate cortical motor regions. A recent study that we conducted with patients suffering from Parkinson's Disease (PD), a neurodegenerative disease primarily characterized by motor disorders, seemed to confirm this assumption (Boulenger, et al., in 
press). In this study, the subliminal display of a word (e.g. TABLE) was used to prime a target word (e.g. table) which was presented overtly shortly afterwards. PD patients were required to make a lexical decision to the overtly displayed target (i.e. deciding whether the stimulus was a word or not) and reaction time was measured. In such "masked priming" paradigms, reaction time is typically faster when prime and target are identical (TABLE-table; e.g. Ferrand et al. 1994), compared to a condition where prime and target are different (CVKLS-table). The results of this study revealed that the receptivity of PD patients for subliminal displays of visual words was conditional on word meaning. When PD patients were off dopaminergic treatment (i.e. when motor disorders were important), they showed a selective deficit to capture information from masked action verbs - but not from masked concrete nouns. That is, while there was little or no priming effect for verbs, strong priming was observed for nouns. Levodopa intake, which re-establishes normal activation level in premotor and motor areas via the striato-frontal loop, then restored the motor disorders as well as the selective deficit for action verbs. These results are thus among the first to directly show that the cortical motor system contributes to the effective processing of action-related language, because the selective deficit for verbs was contingent on the motor disorder. The present study aims at substantiating this finding by analyzing the impact of subliminal action word displays on the neurophysiological correlates of motor preparation (using electroencephalography, EEG) and on the subsequent execution of the movement (using kinematic analyses) in healthy participants.

\section{Electrophysiological indicator of motor processing: the Readiness Potential}

A major part of the motor program that controls movement is computed prior to movement onset and guarantees the efficient organization of the motor act (Requin et al., 1991; Riehle, 2005; Schmidt et al., 1979). A simple observation that highlights the role of these preparatory processes is that providing prior information about movement parameters (e.g. movement direction), or removing uncertainty about when a movement has to be executed, shortens considerably motor reaction time (Riehle, 2005). Given the significant role of preparatory processes for a movement, interferences between language and motor action as previously reported (Boulenger et al. 2006; Nazir et al. in press) should also be observed when action words are processed during motor preparation period. Since the "Readiness Potential" (RP) is a well-known electrophysiological correlate of movement preparatory processes (Kornhuber \& Deecke, 1965; for a review, see Colebatch, 2007), we aimed at analyzing this potential during language processing. 
The RP, which is believed to arise from premotor and primary motor areas, is characterized by a slow negative going potential that starts approximately 1 second prior to movement onset, with maximum amplitudes at centrolateral recording sites (Ball et al., 1999; Cunnington et al., 2003; Deecke \& Kornhuber, 1978; Deecke et al., 1987; Praamstra et al., 1996; Shibasaki et al., 1980). The RP is generally elicited prior to self-paced voluntary movements, but it has also been recorded in relation to stimulus-triggered movements (Castro et al., 2005; Kilner et al., 2004). Moreover, some investigators have regarded the RP as equivalent to the late component of the Contingent Negative Variation $(\mathrm{CNV}$, which is a negative potential recorded prior to cued movements; Walter et al., 1964), in paradigms in which a "warning" stimulus (S1; which gives advanced information about the movement that has to be performed) precedes an "imperative" stimulus (S2) to which participants must react (S1-S2 paradigm; Grünewald et al., 1979; Rockstroh et al., 1982; Rohrbaugh et al., 1976; Rohrbaugh \& Gaillard, 1983).

In the present study, we will use a S2-centered CNV-like paradigm in which subsequent to the presentation of a (visual) preparatory-signal (S1), participants have to quickly reach and grasp an object in response to a (visual) go-signal (S2). During the preparatory period (i.e. the time interval between S1 and S2), action verbs, concrete nouns or strings of consonants will be displayed subliminally on a screen. Using a novel paradigm that combines EEG with kinematic analyses, we will assess the influence of these subliminal displays on the concurrent preparation and subsequent execution of the reaching movement, by determining the impact of each stimulus category on the profile of the $\mathrm{RP}^{1}$ and on kinematic parameters of motor performance.

\section{Predictions}

In line with our previous findings (Boulenger et al., 2006; Nazir et al., in press), we predict that subliminal displays of action verbs during motor preparation will interfere with motor processes and thus delay and/or diminish the amplitude of the RP (less negative), compared to concrete nouns. Moreover, as motor preparation relies on central processes responsible for the

\footnotetext{
${ }^{1}$ In agreement with previous studies (Castro et al., 2005; Kilner et al., 2004), we will use the term RP to denote the here observed movement-related potential. Actually, in our CNV-like paradigm, on appearance of the S1, participants had all necessary information to perform their movement. Since the CNV (also called "expectancy wave") requires that $\mathrm{S} 1$ only delivers partial information about the subsequent movement, that is, one must have a "state of uninformed waiting" during the interstimulus interval (Dimitrov, 2004), we decided not to consider the observed potential as a proper CNV but rather as a RP.
} 
efficient organization of motor performance (Requin et al., 1991; Riehle, 2005), subliminal displays of action words during motor preparation should have repercussions on the execution of the movement. We therefore expect that the latency and/or amplitude of the peak of wrist acceleration will occur later and/or be smaller in the action word condition.

\section{Methods}

\section{Participants}

Twenty-five French native volunteers (mean age $=27.5$ years old) participated in this experiment. All were right-handed (scores between 0.75 to 1; Oldfield, 1971), and had normal or corrected-to-normal vision. All participants gave their written informed consent to the experimental procedure.

\section{Stimuli}

One hundred and forty words (70 verbs and 70 nouns) were selected from the French lexical database "Lexique" (New et al., 2001). Verbs, all in the infinitive form, denoted actions performed with the hand/arm (e.g. write, throw), while nouns, in singular form, referred to imageable concrete entities without specific motor associations (i.e. that cannot be manipulated, e.g. mill, cliff). Words that could be used as both nouns and verbs in French were excluded from the selection. Stimuli were matched for relevant lexical variables including word frequency, length in letters, number of syllables, bi- and trigram frequency (Table 1). Word age-of-acquisition was also controlled using empirical ratings performed by 15 volunteers (who did not participate in the experiment) on a seven-point scale $(1=[0-2$ years] and $7=$ [older than 13 years]; Gilhooly \& Logie, 1980). Word imageability was estimated following the same procedure by another 15 volunteers (who did not participate in the experiment; with $0=$ impossible and $6=$ very easy to generate a mental image of the word).

As a control condition, we also constructed 70 meaningless consonant strings (not pronounceable in French; e.g. szmfr), matched to words for length in letters and visual envelope. For the first group of subjects, consonant strings were matched to a subset of 70 words (35 verbs and 35 nouns), while for the second group, consonant strings were matched for a subset of the 70 remaining words. 


\section{Procedure}

Participants were asked to touch a home-pad $(10 \mathrm{~cm}$ from their chest) with their right thumb and index finger held in a pinch grip position, while fixating a monitor $(65 \mathrm{~cm}$ from their chest). On appearance of a white cross at the centre of the monitor (preparation-signal; $\mathrm{S} 1)$, they had to prepare to leave the home-pad to reach and grasp a small object $(\mathrm{L}=30 \mathrm{~mm}$; $1=15 \mathrm{~mm}$ ) pasted on the screen slightly below the cross. Participants were instructed to prepare but not start the movement before the appearance of the go-signal (S2), which was a white circle, displayed $950 \mathrm{~ms}$ after the onset of S1. The cross, which remained on the screen for $500 \mathrm{~ms}$, was immediately followed by two successively displayed pattern masks (each for a duration of $100 \mathrm{~ms}$ ), followed by a $50 \mathrm{~ms}$ display of the orthographic stimulus (action verb, concrete noun or consonant string), followed by another two successively displayed pattern masks. The last mask was replaced by the go-signal (S2; see Figure 1 for the temporal sequence of the stimuli). Participants were told to pay attention to the entire sequence of the rapidly changing visual display. Upon presentation of S2, they had to perform the reaching and grasping movement as fast and as accurately as possible. The go-signal remained on the screen for 1s (i.e. until participants grasped the object). The next trial was triggered by the experimenter once participants were in the starting position. Participants were asked not to blink during the preparatory period in order to not contaminate the EEG signal. Each orthographic stimulus was displayed once and presentation order was randomized. Ten training trials (different from the experimental session) familiarized participants with the task.

\section{- Insert Figure 1 here -}

\section{Visibility of letter strings}

To determine whether display duration of $50 \mathrm{~ms}$ guaranteed that participants did not consciously perceive the orthographic stimuli, we carried out a pilot study in which stimuli were presented using the same procedure as for the EEG/kinematic experiment (see Figure 1). However, no movement was requested. Participants were explicitly told that the rapid serial visual display could contain words and that their task was to identify as many words as possible. If they perceived a word, they had to name it. Twelve volunteers (different from the participants of the EEG experiment), including 3 members of the laboratory who were highly familiar with rapid visual displays, participated in this pilot study. The results showed that on 
average the 3 highly trained participants could recognize $48.7 \%$ of the words (SD $=8.3 ; 58 \%$, $46 \%$ and $42 \%$ respectively). However, the 9 naïve participants identified only $14 \%$ of the stimuli ( $\mathrm{SD}=11 ; 10 \%$ for concrete nouns and $4 \%$ for action verbs). Given that in the main experiment (naïve) participants did not concentrate on the word recognition task, we considered display duration of $50 \mathrm{~ms}$ to be adequate for our experiment.

\section{Movement acquisition and kinematic analysis}

An Optotrak 3020 (Northern Digital) was used to record the spatial positions of four markers (infrared light-emitting diodes), at a frequency of $200 \mathrm{~Hz}$ and with a spatial resolution of $0.1 \mathrm{~mm}$. One marker, characterizing the reaching component, was taped on the wrist (Jeannerod, 1981; Jeannerod \& Biguer, 1982). The three remaining markers were fixed on the experimental set-up to define a space in which all recorded movements were systematically placed from participant to participant.

A second-order Butterworth dual pass filter (cutoff frequency, $10 \mathrm{~Hz}$ ) was used for raw data processing. Movements were then visualized and analyzed using Optodisp software (Optodisp: copyright INSERM-CNRS-UCBL, Thévenet, Paulignan \& Prablanc, 2001). Kinematic parameters were assessed for each individual movement. We analyzed reaction time (ms; i.e. time elapsed between the onset of the go-signal S2 and movement onset) and latency $(\mathrm{ms})$ and amplitude $\left(\mathrm{mm} / \mathrm{s}^{2}\right)$ of wrist acceleration peak. This last kinematic parameter was chosen since it constitutes an excellent indicator of reaction to on-line perturbation during movement execution (Paulignan et al., 1991). Movement onset was determined as the first value of a sequence of at least eleven increasing points on the basis of wrist velocity profile. End of movements were determined similarly starting from the end and going backward. Peak latency was defined as the time elapsed between movement onset and peak. Both kinematic parameters were determined for each individual trial and were then averaged for each participant as a function of the three experimental conditions (action verbs, concrete nouns and consonant strings). Trials in which participants made errors or anticipated movement execution were excluded from the analysis. Analyses of variance (ANOVAs) with repeated measures were used to assess significant differences between the three stimulus categories. Post-hoc tests (Newman-Keuls) were performed to dissociate effects of each stimulus category on the kinematic parameters. 
Thirty-two sintered $\mathrm{Ag} / \mathrm{AgCl}$ ring electrodes were placed on elastic caps (ECI Electro-Cap, Electro-Cap International, Inc., USA) matched to the head size of each subject. EEG activity was recorded continuously from these 32 electrodes positioned according to the international 10-20 system (BrainAmp MR, Brain Products GmbH, Munich, Germany), referenced against Fp2. Horizontal and vertical electro-oculograms (hEOG and vEOG respectively) were recorded from bipolar electrodes placed on the left outer canthus and below the left eye respectively. EEG and EOG signals were sampled at $500 \mathrm{~Hz}$, and system band pass was 0.016-250 Hz. Electrode impedance was kept below $10 \mathrm{k} \Omega$ throughout the experiment.

EEG data were processed using BrainAmp Analyze software. The EEG was first filtered (band-pass $0.01-30 \mathrm{~Hz}, 48 \mathrm{~dB} /$ octave), and re-referenced to a common average reference including Fp2. Data were then EOG corrected to account for ocular artifact (Gratton et al., 1983). Data were segmented from $980 \mathrm{~ms}$ prior to the onset of S2 to $700 \mathrm{~ms}$ post onset, and baseline corrected (over a window of $100 \mathrm{~ms}$ prior to the onset of the first visual stimulus). Epochs in which the EEG or EOG exceeded $\pm 200 \mu \mathrm{V}$ were rejected. All trials were averaged time-locked to the go-signal S2 (i.e. t0 corresponds to S2 onset) separately for the three experimental conditions (action verbs, concrete nouns and consonant strings).

\section{Readiness Potential.}

Since the RP response is most prominent over the central scalp region, the $\mathrm{Cz}$ electrode was defined as the region of interest. The window of interest was calculated from the average $\mathrm{RP}$ for each participant. This time-window was defined from word onset ( $250 \mathrm{~ms}$ prior to the go-signal) to the most negative point prior to movement onset (approximately 100-150 ms after the go-signal). For each participant and for every condition, a line of best fit was calculated for the RP in this window of interest. The gradient of this fitted line was used for statistical analyses. A series of Wilcoxon Signed-Rank Tests were performed, with an independent variable of stimulus condition (action verbs, concrete nouns and consonant strings), and a dependant variable of RP gradient. Non-parametric tests were employed as the data could not be normally distributed. Note that an additional analysis of the RP over a central region including electrodes surrounding $\mathrm{Cz}(\mathrm{FC} 1, \mathrm{FC} 2, \mathrm{C} 1, \mathrm{C} 2, \mathrm{Cz})$ led to the same results - albeit less strong - as the analysis based only on $\mathrm{Cz}$.

\section{Results}


Data from seven participants were excluded from the kinematic analyses and from eleven from the EEG analyses. Four of the discarded participants showed steadily increasing performance (i.e. strong learning effects as indicated by a systematic increase of the amplitude of the wrist acceleration peak) and were removed from both analyses. For EEG analyses, three participants were further excluded as they did not show a RP, and four others because of a too noisy signal. For analyses of movement kinematics, two participants were excluded because of high percentage ( $>30 \%$ ) of movement anticipation (i.e. onset of the movement prior to the S2). However, these participants were not excluded from EEG analyses since anticipation may reflect efficient motor preparation. Kinematic and EEG results are thus presented for 18 and 14 participants respectively. Seven out of these remaining participants reported to have perceived letters during the preparation period, but did not recognize the words.

\section{Kinematic results}

Average reaction time was very short (122 ms) and did not differ between conditions (120 for verbs, $122 \mathrm{~ms}$ for nouns and $125 \mathrm{~ms}$ for consonant strings). The short latency of reaction time is indicative that participants effectively prepared to perform the movement. Kinematic analyses revealed that individual wrist acceleration peaks were smaller in amplitude in the action verb condition than in the concrete noun condition (Table 2). A repeated measures ANOVA confirmed that stimulus category significantly affected this variable $([\mathrm{F}(2,16)=$ $4.214 ; \mathrm{p}=.0232])$. Post-hoc analysis showed that the amplitude of the wrist acceleration peak was significantly reduced during subliminal presentation of action verbs $\left(8059 \mathrm{~mm} / \mathrm{s}^{2} \pm 4333\right)$ when compared to concrete nouns $\left(8238 \mathrm{~mm} / \mathrm{s}^{2} \pm 4597, \mathrm{p}=.0360\right)$. This pattern was observed for 15 of the 18 participants. A similar reduction of the amplitude of wrist acceleration was also observed for the consonant string condition when compared to the noun condition (8099 $\mathrm{mm} / \mathrm{s}^{2} \pm 4331, \mathrm{p}=.0252$; this pattern was observed for 14 of the 18 participants), but no significant difference was observed between action verb and consonant string conditions.

- Insert Table 2 here-

EEG results: Signature of motor processes.

ERP data revealed a strong RP over the central region (Figure 2), indicating preparation to perform the reaching movement. 
Table 3 plots values for slope, intercept and $\mathrm{R}^{2}$ of the $\mathrm{RP}$ gradient for individual participants. Wilcoxon signed-rank tests showed a significant effect of stimulus category on the gradient of the RP following stimulus presentation. The slope of the RP gradient for the action verb condition (mean $=-0.0270 \pm 0.017$ ) was significantly smaller compared to the concrete noun condition (mean $=-0.0299 \pm 0.019 ; \mathrm{T}=23, \mathrm{p}<.05$, one-tailed). This pattern was observed in 11 out of the 14 participants. Note that over a time-window of -300 to -350 $\mathrm{ms}$, the difference in mean slope represents approximately $1 \mu \mathrm{V}$ of amplitude. There was also a trend-level decrease in the RP gradient for consonant strings (mean $=-0.0273 \pm 0.015$ ) compared to concrete nouns (mean $=-0.0299 \pm 0.019 ; \mathrm{T}=25.5, \mathrm{p}=.09$, two-tailed; .045 , onetailed), but similar to the kinematic data, no significant difference was found between action verbs and consonant strings $(T=50.5, \mathrm{p}=.90)$.

- Insert Table 3 here-

\section{General discussion}

Assuming that processing of action verbs and motor planning share common neural substrates, the present study aimed at revealing patterns of interaction between language and motor processes by analyzing the impact of subliminal action word displays on the neurophysiological correlates of motor preparation and on the kinematics of the subsequent movement. The results, summarized in Figure 3, revealed the following: First, consistent with our previous findings (Boulenger et al., 2006; Nazir et al., in press), analyses of kinematic parameters showed that subliminal displays of action verbs during movement preparation affected the execution of a reaching movement more than subliminal displays of concrete nouns. Second, ERPs analyses revealed that the slope of the movement-preceding RP (an indicator of movement preparation) was less negative following a verb than following a noun.

Note that subliminal displays of random strings of consonants during movement preparation had a similar impact on movement kinematics and on the RP as subliminal displays of action verbs. No clear explanation for this finding can be offered since strings of consonants should not activate the cortical network for word recognition. One possible 
account for the present finding may be that by matching the visual envelopes of consonant strings to words (i.e. the outer shape of the overall letter chain), low spatial frequency features of consonant strings have accidentally become compatible with verb stimuli. Given that the main goal of this study was to compare action verbs and concrete nouns, we will discuss the results obtained for these two word categories without further referring to the strings of consonants.

\section{- Insert Figure 3 here -}

The analyses of kinematic parameters and RP both revealed that subliminal displays of action verbs during movement preparation had a stronger impact on ongoing motor processes than subliminal displays of concrete nouns. These results support and extend our previous findings (Boulenger et al., 2006; Nazir et al., in press) by demonstrating that processing action words do not only interfere with movement execution but also with movement preparation. In line with our previous results (see also Pulvermüller et al., 2005a), the observed cross-talk between language and motor processes further emerged early following verb onset. Since words were displayed in the second half of the preparatory period, which is known to engage both premotor and primary motor cortex (Ball et al., 1999; Cui et al., 1999), our results are also consistent with neuroimaging studies that show activity in motor and premotor cortex during processing of action-related words or sentences (Aziz-Zadeh et al., 2006; Hauk et al., 2004; Tettamanti et al., 2005). Note that, in the present study, action verbs and concrete nouns differed both on action-relatedness and grammatical class. One may therefore argue that the language-induced effects we found on movement preparation/execution could be explained by this grammatical class confound. However, considering previous studies that showed similar cortical activations over the motor cortex for action-related nouns and verbs (but not for action-related and visually-related nouns; Oliveri et al., 2004; Pulvermüller et al., 1999b), we suggest that our results are more plausibly explained by semantic differences between word categories (action- and non-action-related).

The present study further established that mental motor imagery that may occur after a word has been identified cannot account for the observed language-induced motor perturbation, as words were not perceived consciously. As mentioned in the introduction, fMRI studies have previously shown that subliminal word displays can automatically preactivate essential parts of the cerebral networks for word processing (Dehaene et al., 2001). 
Selective activation of cortical and sub-cortical areas during subliminal perception of words that belong to a particular semantic category has also been reported previously. For instance, Naccache et al. (2005) showed that activity in the amygdala, which is known to respond to fearful or threatening stimuli, is modulated during subliminal displays of fearful words. Similarly, Naccache and Dehaene (2001) showed that intraparietal cortex, which plays a role in the mental representation of numerical quantity (Dehaene \& Cohen, 1995; Dehaene et al., 1998), is recruited during processing of masked number words. Naccache and colleagues interpreted their data as showing that an extended stream of word processing stages can be activated despite the fact that words are not consciously perceived. The present study adds to this picture by showing that subliminal displays of action words modulate cortical motor processes and affect overt motor behavior. But more importantly, together with the results reported for the PD patients (Boulenger et al. in press), the present findings clearly suggest that cortical structures that serve the preparation and execution of motor actions are essential for the effective processing of action-related language.

Our estimation of the slope parameter for the RP suggested that, within less than $400 \mathrm{~ms}$ following masked action word displays (i.e. the time-window that served to determine the slope parameter), the amplitude of the RP was reduced by approximately $1 \mu \mathrm{V}$ compared to conditions where non-action words were displayed. The impact of action words on brain potentials that indicate motor processes thus becomes evident shortly after word onset, despite the fact that participants do not perceive the words consciously. This interference between the two tasks is likely due to competition for common cortical resources (Boulenger et al., 2006) and should, in principle, penalize motor processes as well as language processes. In the present study, we did not measure performance for language processing. However, the results of our PD patients off treatment who showed masked priming effects for concrete nouns but not for action verbs (Boulenger et al. in press) clearly indicated that a pathology that affects the normal functioning of premotor and motor areas selectively wipes out the benefit of subliminal displays of action words in a task that probes language processing.

In conclusion, the present study, which for the first time combined EEG and kinematic measures, reveals that subliminal perception of action verbs, relative to concrete nouns, can interfere with the concurrent preparation and the subsequent execution of an arm reaching movement. Overall, our results therefore confirm previous findings and support the assumption that language-related activity in motor areas is indeed part of word processing and 
that motor areas contribute to action word understanding.

\section{Bibliography}

Aziz-Zadeh, L., Wilson, S.M., Rizzolatti, G. \& Iacoboni, M. (2006). Congruent embodied representations for visually presented actions and linguistic phrases describing actions. Current Biology, 16, 1818-1823.

Ball, T., Schreiber, A., Feige, B., Wagner, M., Lucking, C.H. \& Kristeva-Feige, R. (1999). The role of higher-order motor areas in voluntary movement as revealed by high-resolution EEG and fMRI. Neuroimage, 10(6), 682-694.

Boulenger, V., Roy, A.C., Paulignan, Y., Déprez, V., Jeannerod, M. \& Nazir, T.A. (2006). Cross-talk between language processes and overt motor behavior in the first $200 \mathrm{~ms}$ of processing. Journal of Cognitive Neuroscience, 18(10), 1607-1615.

Boulenger, V., Mechtouff, L., Thobois, S., Broussolle, E., Jeannerod, M. \& Nazir, T.A. (in press). Word processing in Parkinson's Disease is impaired for action verbs but not for concrete nouns. Neuropsychologia.

Buccino, G., Riggio, L., Melli, G., Binkofski, F., Gallese, V. \& Rizzolatti, G. (2005). Listening to action-related sentences modulates the activity of the motor system: a combined TMS and behavioral study. Cognitive Brain Research, 24(3), 355-363.

Castro, A., Diaz, F. \& van Boxtel, G.J. (2005). What happens to the readiness potential when the movement is not executed? Neuroreport, 16(5), 1609-1613.

Cohen, L. \& Dehaene, S. (2004). Specialization within the ventral stream: the case for the visual word form area. Neuroimage, 22(1), 466-476.

Colebatch, J.G. (2007). Bereitschaftspotential and movement-related potentials: origin, significance, and application in disorders of human movement. Movement Disorders, 22(5), 601-610.

Cunnington, R., Windischberger, C., Deecke, L. \& Moser, E. (2003). The preparation and readiness for voluntary movement: a high-field event-related fMRI study of the Bereitschafts-BOLD response. Neuroimage, 20(1), 404-412.

Deecke, L. \& Kornhuber, H.H. (1978). An electrical sign of participation of the mesial "supplementary" motor cortex in human voluntary finger movement. Brain and Research, 159, 473-476.

Deecke, L., Lang, W., Heller, H.J., Hufnagl, M. \& Kornhuber, H.H. (1987). Bereitschaftspotential in patients with unilateral lesions of the supplementary motor area. Journal of Neurology, Neurosurgery and Psychiatry, 50, 1430-1434.

Dehaene, S. \& Cohen, L. (1995). Towards an anatomical and functional model of number processing. Math Cogn, 1, 83-120.

Dehaene, S., Naccache, L., Le Clec'H, G., Koechlin, E., Mueller, M., Dehaene-Lambertz, G., van de Moortele, PF., Le Bihan, D. (1998). Imaging unconscious semantic priming. Nature, 395(6702), 597-600.

Dehaene, S., Naccache, L., Cohen, L., Bihan, D.L., Langin, J.F., Poline, J.B. \& Riviere, D. (2001). Cerebral mechanisms of word masking and unconscious repetition priming. Nature Neuroscience, 4(7), $752-758$.

Fadiga, L. \& Craighero, L. (2004). Electrophysiology of action representation. Journal of Clinical Neurophysiology, 21(3), 157-169.

Ferrand, L., Grainger, J. \& Segui, J. (1994). A study of masked form priming in picture and word naming. Memory and Cognition, 22(4), 431-441.

Fischer, M. \& Zwaan, (in press). Embodied language- A review of the role of the motor systems in language comprehension. The Quarterly Journal of Experimental Psychology.

Forster, K.I. (1999). The microgenesis of priming effects in lexical access. Brain \& Language, Special Issue: Mental lexicon, 68(1-2), 5-15.

Forster, K.I. \& Davis, C. (1984). Repetition priming and frequency attenuation in lexical access. Journal of Experimental Psychology: Learning, Memory, and Cognition, 10, 680-698. 
Gallese, V. \& Lakoff, G. (2005). The brain's concepts: The role of the sensory-motor system in conceptual knowledge. Cognitive Neuropsychology, 22, 455-479.

Geisser, S. \& Greenhouse, S. (1959). On methods in analysis of profile data. Psychometrika, 24, 94112.

Gilhooly, K.J., \& Logie, R.H. (1980). Methods and designs: Age of acquisition, imagery, concreteness, familiarity, and ambiguity measures for 1,944 words. Behaviour Research Methods and Instrumentation, 12, 395-427.

Glover, S., Rosenbaum, D.A., Graham, J. \& Dixon, P. (2004). Grasping the meaning of words. Experimental Brain Research, 154(1), 103-108.

Gratton, G., Coles, M.G. \& Donchin, E. (1983). A new method for off-line removal of ocular artifact. Electroencephalography and Clinical Neurophysiology, 55(4), 468-484.

Grünewald, G., Grünewald-Zuberbier, E., Netz, J., Homberg, V. \& Sander, G. (1979). Relationships between the late component of the contingent negative variation and the bereitschaftspotential. Electroencephalography and Clinical Neurophysiology, 46(5), 538-545.

Hauk, O., Johnsrude, I. \& Pulvermüller, F. (2004). Somatotopic representation of action words in human motor and premotor cortex. Neuron, 41, 301-307.

Hauk, O., Patterson, K., Woollams, A., Watling, L., Pulvermüller, F. \& Rogers, T.T. (2006). When would you prefer a SOSSAGE to a SAUSAGE? At about $100 \mathrm{msec}$. ERP correlates of orthographic typicality and lexicality in written word recognition. Journal of Cognitive Neuroscience, 18(5), 818-832.

Jeannerod, M. (1981). Intersegmental coordination during reaching at natural visual objects. In: Long, J. \& Baddeley A. (Eds). Attention and Performance IX. Lawrence Erlbaum Associates Publishers, Hillsdale (NJ), 153-168.

Jeannerod, M. \& Biguer, B. (1982). Visuomotor mechanisms in reaching within extrapersonal space. In: Ingle D, Goodale, M. A. \& Mansfield, R. (eds). Advances in the analysis of visual behavior. MIT Press, Boston, 387-409.

Jeannerod, M. (1994). The representing brain: Neural correlates of motor intention and imagery. Behavioral and Brain Sciences, 17(2), 187-524.

Kilner, J.M., Vargas, C., Duval, S. Blakemore, S.J. \& Sirigu, A. (2004). Motor activation prior to observation of a predicted movement. Nature Neuroscience, 7(12), 1299-1301.

Kornhuber, H.H. \& Deecke, L. (1965). Changes in the brain potential in voluntary movements and passive movements in man: readiness potential and reafferent potential. Pflugers Arch Gesamte Physiol Menschen Tiere, 284, 1-17.

Marcel, A.J. (1983). Conscious and unconscious perception: Experiments on visual masking and recognition. Cognitive Psychology, 15, 197-237.

Naccache, L. \& Dehaene, S. (2001). Unconscious semantic priming extends to novel unseen stimuli. Cognition, 80(3), 215-229.

Naccache, L., Gaillard, R., Adam, C., Hasboun, D., Clemenceau, S., Baulac, M., Dehaene, S. \& Cohen, L. (2005). A direct intracranial record of emotions evoked by subliminal words. Proceedings of the National Academy of Sciences, USA, 102(21), 7713-7717.

Nazir, T.A., Boulenger, V., Roy, A.C., Silber, B.Y., Jeannerod, M. \& Paulignan, Y. (in press). Language-induced motor perturbations during the execution of a reaching movement. Quarterly Journal of Experimental Psychology.

Oliveri, M., Finocchiaro, C., Shapiro, K., Gangitano, M., Caramazza, A. \& Pascual-Leone, A. (2004). All talk and no action: a transcranial magnetic stimulation study of motor cortex activation during action word production. Journal of Cognitive Neuroscience, 16(3), 374-381.

Paulignan, Y., MacKenzie, C. L., Marteniuk, R.G. \& Jeannerod, M. (1991). Selective perturbation of visual input during prehension movements. 1. The effects of changing object position. Experimental Brain Research, 83, 502-512.

Praamstra, P., Stegeman, D., Horstink, M.W. \& Cools, A.R. (1996). Dipole source analysis suggests selective modulation of the supplementary motor area contribution to the readiness potential. Electroencephalography and Clinical Neurophysiology, 98(6), 468-477.

Preissl, H., Pulvermüller, F. Lutzenberger, W. \& Birbaumer, N. (1995). Evoked potentials distinguish between nouns and verbs. Neuroscience Letters, 197, 81-83. 
Pulvermüller, F. (1996). Hebb's concept of cell assemblies and the psychophysiology of word processing. Psychophysiology, 33, 317-333.

Pulvermüller, F., Lutzenberger, W. \& Preissl, H. (1999a). Nouns and verbs in the intact brain: Evidence from event-related potentials and high-frequency cortical responses. Cerebral Cortex, 9, 497-506.

Pulvermüller, F., Mohr, B. \& Schleichert, H. (1999b). Semantic or lexico-syntactic factors: what determines word-class specific activity in the human brain? Neuroscience Letters, 275(2), 81-84.

Pulvermüller, F. (2001). Brain reflections of words and their meaning. Trends in Cognitive Sciences, 5, 517-525.

Pulvermüller, F. (2005). Brain mechanisms linking language and action. Nature Reviews Neuroscience, 6, 576-582.

Pulvermüller, F., Shtyrov, Y. \& Ilmoniemi, R. (2005a). Brain signatures of meaning access in action word recognition. Journal of Cognitive Neuroscience, 17(6), 1-9.

Pulvermüller, F., Hauk, O., Nikulin, V.V. \& Ilmoniemi, R.J. (2005b). Functional links between motor and language systems. European Journal of Neuroscience, 21(3), 793-797.

Requin, J., Brener, J. \& Ring, C. (1991). Preparation for action, in Handbook of Cognitive Psychophysiology: Central and Autonomous Nervous System Approaches, Jennings, R. R. and Coles, M. G. H., Eds., John Wiley \& Sons, New York, 357.

Riehle, A. (2005). Preparation for action: one of the key functions of the motor cortex. In Riehle, A. \& Vaadia, E. (Eds), Motor Cortex in Voluntary Movements: a Distributed System for Distributed Functions, CRC-Press, Boca Raton, FL, pp. 213-240.

Rizzolatti, G. \& Arbib, M.A. (1998). Language within our grasp. Trends in Neurosciences, 21(5), 188194.

Rizzolatti, G., Fogassi, L. \& Gallese, V. (2001). Neurophysiological mechanisms underlying the understanding and imitation of action. Nature Reviews Neuroscience, 2(9), 661-670.

Rockstroh, B., Elbert, T., Birbaumer, N. \& Lutzenberger, W. (1982). Slow brain potentials and behavior. Urban \& Schwarzenberg, Baltimore-Munich, p.274.

Rohrbaugh, J.W., Syndulko, K. \& Lindsley, D.B. (1976). Brain wave components of the contingent negative variation in humans. Science, 191, 1055-1057.

Rohrbaugh, J. \& Gaillard, A.W.K. (1983). Sensory and motor aspects of the contingent negative variation. In A.W.K. Gaillard \& W. Ritter (Eds.), Tutorials in ERP research: Endogenous components. Amsterdam: Elsevier.

Schmidt, R.A., Zelaznik, H.N. \& Frank, J.S. (1979). Sources of inaccuracy in rapid movement. In Stelmach, G.E. (Ed.), Information Processing in Motor Control and Learning. (pp.183-203). NY: Academic Press.

Sereno, S.C., Rayner, K. \& Posner, M. I. (1998). Establishing a time-line of word recognition: evidence from eye movements and event-related potentials. Neuroreport, 9(10), 2195-2200.

Sereno, S.C. \& Rayner, K. (2003). Measuring word recognition in reading: eye movements and eventrelated potentials. Trends in Cognitive Sciences, 7(11), 489-493.

Tettamanti M., Buccino, G., Saccuman, M.C., Gallese, V., Danna, M., Scifo, P., Fazio, F., Rizzolatti, G., Cappa, S.F. \& Perani, D. (2005). Listening to action-related sentences activates fronto-parietal motor circuits. Journal of Cognitive Neuroscience, 17, 273-281.

Thévenet, M., Paulignan, Y.\& Prablanc, C. (2001). OPTODISP Program, License INSERMCNRS-UCBL.

Walter, W.G., Cooper, R., Aldridge, V.J., McCallum, W.C. \& Winter, A.L. (1964). Contingent Negative Variation: an electric sign of sensorimotor association and expectancy in the human brain. Nature, 203, 280-284.

Zwaan, R.A. \& Taylor, L.J. (2006). Seeing, acting, understanding: motor resonance in language comprehension. Journal of Experimental Psychology, General, 135(1), 1-11. 
Table 1: Mean values of word frequency (FQ), length in letters (LETT), number of syllables (SYLL), bigram frequency (BIGR), trigram frequency (TRIG), age-of-acquisition (AoA) and imageability (IMAG) are reported for concrete nouns and action verbs. ANOVAs by items are reported in the last column of the table. (ns), non significant.

\begin{tabular}{|l|c|c|c|}
\cline { 2 - 4 } \multicolumn{1}{c|}{} & Nouns & Verbs & ANOVAs (by items) \\
\hline FQ & 10.53 & 10.4 & {$[\mathrm{~F}(1,138)=.0006 ; \mathrm{p}=\mathrm{ns}]$} \\
\hline LETT & 6.57 & 6.57 & $* * * * *$ \\
\hline SYLL & 2.11 & 2.24 & {$[\mathrm{~F}(1,138)=1.737 ; \mathrm{p}=\mathrm{ns}]$} \\
\hline BIGR & 4109 & 4676 & {$[\mathrm{~F}(1,138)=1.842 ; \mathrm{p}=\mathrm{ns}]$} \\
\hline TRIG & 505 & 571 & {$[\mathrm{~F}(1,138)=.5321 ; \mathrm{p}=\mathrm{ns}]$} \\
\hline AoA & 4.38 & 4.11 & {$[\mathrm{~F}(1,138)=1.556 ; \mathrm{p}=\mathrm{ns}]$} \\
\hline IMAG & 4.48 & 4.22 & {$[\mathrm{~F}(1,138)=3.196 ; \mathrm{p}=\mathrm{ns}]$} \\
\hline
\end{tabular}

Table 2: Mean latency $(\mathrm{ms})$ and amplitude $\left(\mathrm{mm} / \mathrm{s}^{2}\right)$ of the wrist acceleration for each participant while concrete nouns, action verbs and meaningless consonant strings had been subliminally presented during the preparatory period of the reaching movement. Last three rows: Mean overall participants, Standard Deviation (SD) and ANOVA with repeated measures (ns, non significant).

\begin{tabular}{|c|c|c|c|c|c|c|}
\hline \multirow[b]{3}{*}{ Participants } & \multicolumn{6}{|c|}{ Wrist Acceleration Peak } \\
\hline & \multicolumn{3}{|c|}{ LATENCY (ms) } & \multicolumn{3}{|c|}{ AMPLITUDE $\left(\mathrm{mm} / \mathrm{s}^{2}\right)$} \\
\hline & $\begin{array}{l}\text { CONCRETE } \\
\text { NOUNS }\end{array}$ & $\begin{array}{l}\text { ACTION } \\
\text { VERBS }\end{array}$ & $\begin{array}{c}\text { CONSONANT } \\
\text { STRINGS }\end{array}$ & $\begin{array}{c}\text { CONCRETE } \\
\text { NOUNS }\end{array}$ & $\begin{array}{l}\text { ACTION } \\
\text { VERBS }\end{array}$ & $\begin{array}{c}\text { CONSONANT } \\
\text { STRINGS }\end{array}$ \\
\hline P1 & 228 & 228 & 220 & 4243 & 4215 & 4144 \\
\hline P2 & 266 & 269 & 275 & 2287 & 2211 & 2260 \\
\hline P3 & 231 & 213 & 221 & 5144 & 4882 & 4990 \\
\hline P4 & 170 & 179 & 167 & 8995 & 8811 & 8896 \\
\hline P5 & 166 & 171 & 168 & 7848 & 7732 & 7633 \\
\hline P6 & 240 & 242 & 236 & 5531 & 5489 & 5480 \\
\hline P7 & 192 & 193 & 202 & 6662 & 6339 & 6570 \\
\hline P8 & 181 & 182 & 181 & 11529 & 10981 & 10887 \\
\hline P9 & 110 & 119 & 107 & 10430 & 10135 & 10159 \\
\hline P10 & 173 & 183 & 181 & 6737 & 6888 & 7181 \\
\hline P11 & 238 & 225 & 224 & 6113 & 5868 & 5985 \\
\hline P12 & 222 & 242 & 240 & 6813 & 6782 & 6742 \\
\hline P13 & 170 & 158 & 152 & 8160 & 8048 & 8059 \\
\hline P14 & 238 & 235 & 226 & 4859 & 4795 & 4997 \\
\hline P15 & 116 & 108 & 117 & 22735 & 21234 & 21412 \\
\hline P16 & 182 & 183 & 179 & 11402 & 11202 & 11293 \\
\hline P17 & 172 & 162 & 165 & 5812 & 5879 & 5743 \\
\hline P18 & 93 & 85 & 102 & 13338 & 13564 & 13360 \\
\hline MEAN & 188 & 188 & 187 & 8238 & 8059 & 8099 \\
\hline SD & 49 & 50 & 48 & 4597 & 4333 & 4331 \\
\hline ANOVA & & ns & & {$[\mathrm{F}(2,3$} & ) $=4.2145 ;$ & $=.0232]$ \\
\hline
\end{tabular}


Table 3: Values of the slope, intercept and $\mathrm{R}^{2}$ of the RP gradient for each of the 14 participants of the EEG experiment (P1-P14) and for each stimulus category (concrete nouns, action verbs and consonant strings). Means (in bold) and standard deviations (SD) are given in the last two rows of the table.

\begin{tabular}{|c|c|c|c|c|c|c|c|c|c|}
\hline \multirow[b]{2}{*}{ Participants } & \multicolumn{3}{|c|}{ Slope } & \multicolumn{3}{|c|}{ Intercept } & \multicolumn{3}{|c|}{$\mathrm{R}^{2}$} \\
\hline & $\begin{array}{c}\text { Concrete } \\
\text { Nouns }\end{array}$ & $\begin{array}{l}\text { Action } \\
\text { Verbs }\end{array}$ & $\begin{array}{c}\text { Consonant } \\
\text { Strings }\end{array}$ & $\begin{array}{c}\text { Concrete } \\
\text { Nouns }\end{array}$ & $\begin{array}{l}\text { Action } \\
\text { Verbs }\end{array}$ & $\begin{array}{c}\text { Consonant } \\
\text { Strings }\end{array}$ & $\begin{array}{c}\text { Concrete } \\
\text { Nouns }\end{array}$ & $\begin{array}{l}\text { Action } \\
\text { Verbs }\end{array}$ & $\begin{array}{c}\text { Consonant } \\
\text { Strings }\end{array}$ \\
\hline P1 & -0.0123 & -0.0072 & \begin{tabular}{|c|}
-0.0063 \\
\end{tabular} & 0.4756 & 1.4544 & 1.4599 & 0.6883 & 0.3268 & 0.2792 \\
\hline $\mathrm{P} 2$ & -0.0337 & -0.0277 & -0.0291 & 3.5992 & 4.5381 & 3.2932 & 0.7136 & 0.7705 & 0.7406 \\
\hline P3 & -0.0354 & -0.0246 & -0.0328 & 1.2445 & 0.9188 & 1.4492 & 0.9687 & 0.7358 & 0.9524 \\
\hline P4 & -0.0111 & -0.0067 & -0.0063 & 7.9763 & 9.2072 & 8.054 & 0.1423 & 0.056 & 0.0504 \\
\hline P5 & -0.0143 & -0.0107 & -0.0119 & 2.364 & 3.7163 & 4.1086 & 0.2886 & 0.3317 & 0.2995 \\
\hline P6 & -0.0748 & -0.0599 & -0.0497 & 1.6827 & 3.3002 & 3.8341 & 0.9427 & 0.9092 & 0.914 \\
\hline P7 & -0.0205 & -0.0157 & -0.0236 & 3.5982 & 3.9596 & 3.7951 & 0.7372 & 0.8411 & 0.9182 \\
\hline P8 & -0.0163 & -0.0209 & -0.0175 & 2.1727 & 2.3387 & 2.3397 & 0.7004 & 0.7737 & 0.7968 \\
\hline P9 & -0.0184 & -0.0181 & -0.0162 & 4.1901 & 4.1584 & 4.6804 & 0.5092 & 0.5482 & 0.4421 \\
\hline P10 & -0.0606 & -0.0577 & -0.0583 & 3.4664 & 3.2974 & 3.5553 & 0.8834 & 0.9258 & 0.8475 \\
\hline P11 & -0.0478 & -0.0467 & -0.0392 & 1.4014 & 1.9028 & 1.6814 & 0.9322 & 0.8806 & 0.7099 \\
\hline P12 & -0.0199 & -0.0279 & -0.037 & 0.869 & 1.5249 & 1.4026 & 0.6676 & 0.7863 & 0.8047 \\
\hline P13 & -0.0303 & -0.0277 & -0.0293 & 0.3689 & 0.4168 & 0.6959 & 0.8298 & 0.7799 & 0.8206 \\
\hline P14 & -0.0238 & -0.0262 & -0.0248 & 1.756 & 1.3763 & 1.65 & 0.6986 & 0.8532 & 0.7701 \\
\hline MEAN & -0.0299 & -0.027 & \begin{tabular}{|c|}
-0.0273 \\
\end{tabular} & 2.5118 & 3.0079 & 3 & 0.693 & 0.6799 & 0.6676 \\
\hline SD & 0.0192 & 0.017 & 0.0154 & 1.9927 & 2.2135 & 1.9206 & 0.2409 & 0.2636 & 0.2817 \\
\hline
\end{tabular}


Figure 1: Temporal sequence of the stimuli. Grey boxes schematically represent the different stimuli. S1 = Preparation-signal (“+”); M1 = mask $1(\# \# \# \# \# \#) ;$ M2 = mask 2 (\$\$\$\$\$\$); Stim = action verb, concrete noun or consonant-string; M1' and M2' are identical to M1 and M2; S2 = Go-signal (white circle). Numerals plotted under each box denote corresponding display durations in milliseconds. The oblique axis on the right illustrates the temporal sequence of the stimuli and gives the onset of the corresponding item (time 0 corresponds to the onset of S1).

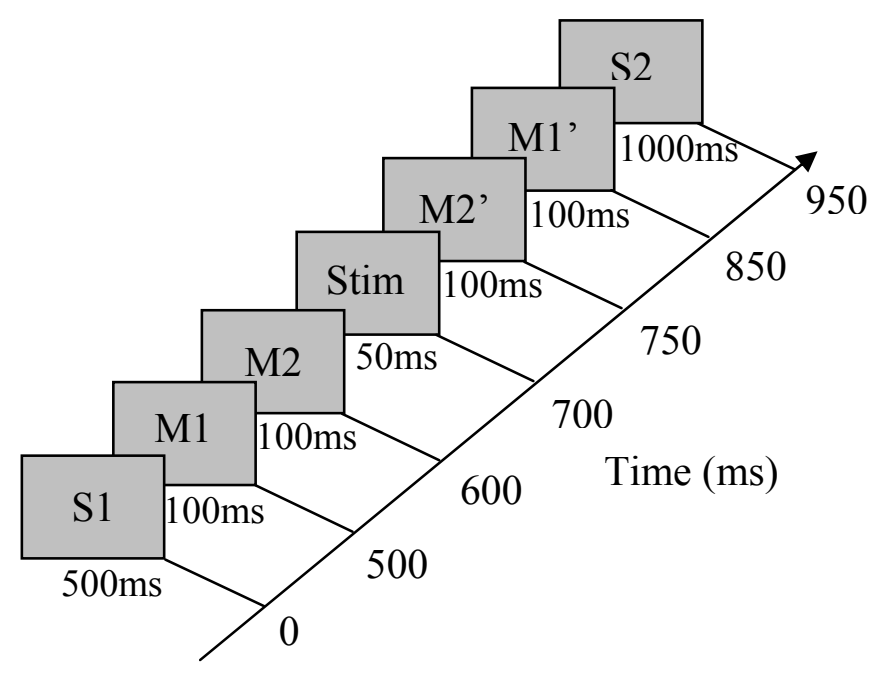


Figure 2: Amplitude $(\mu \mathrm{V})$ of the Readiness Potential as a function of time (ms) for the three experimental conditions (concrete nouns in blue, action verbs in red and consonant strings in black). The time-window (black rectangle) in which significant differences were found between stimulus categories is from word onset $(-250 \mathrm{~ms})$ to movement onset $(\sim 100 \mathrm{~ms})$. Onset of the go-signal is indicated by the dashed vertical line (time 0 ).

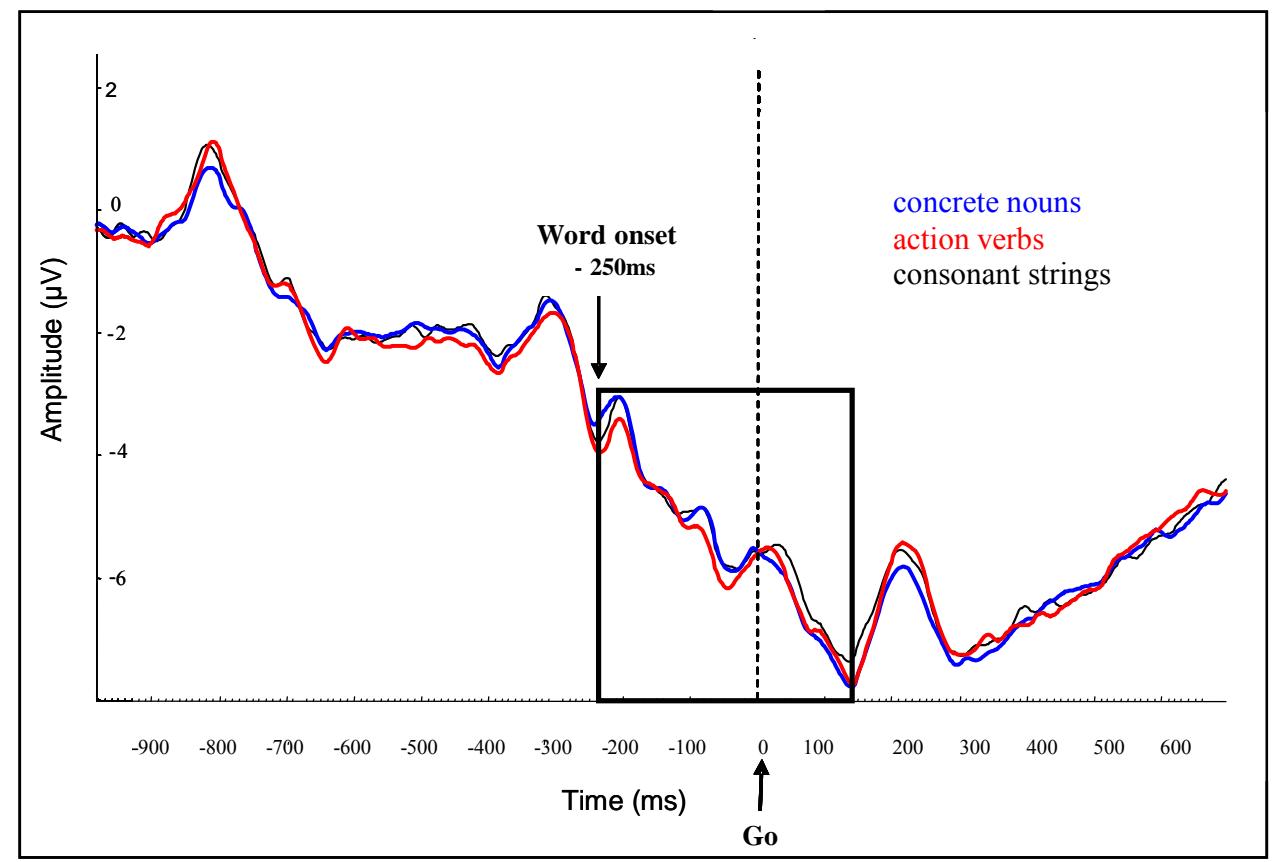

Figure 3: Left panel: Mean gradient of the slope of the RP. Right panel: Mean amplitude of the wrist acceleration peak. Data are plotted as a function of stimulus condition (Concrete Nouns in black, and Action Verbs in grey). The "*” indicates a significant difference between the two conditions.
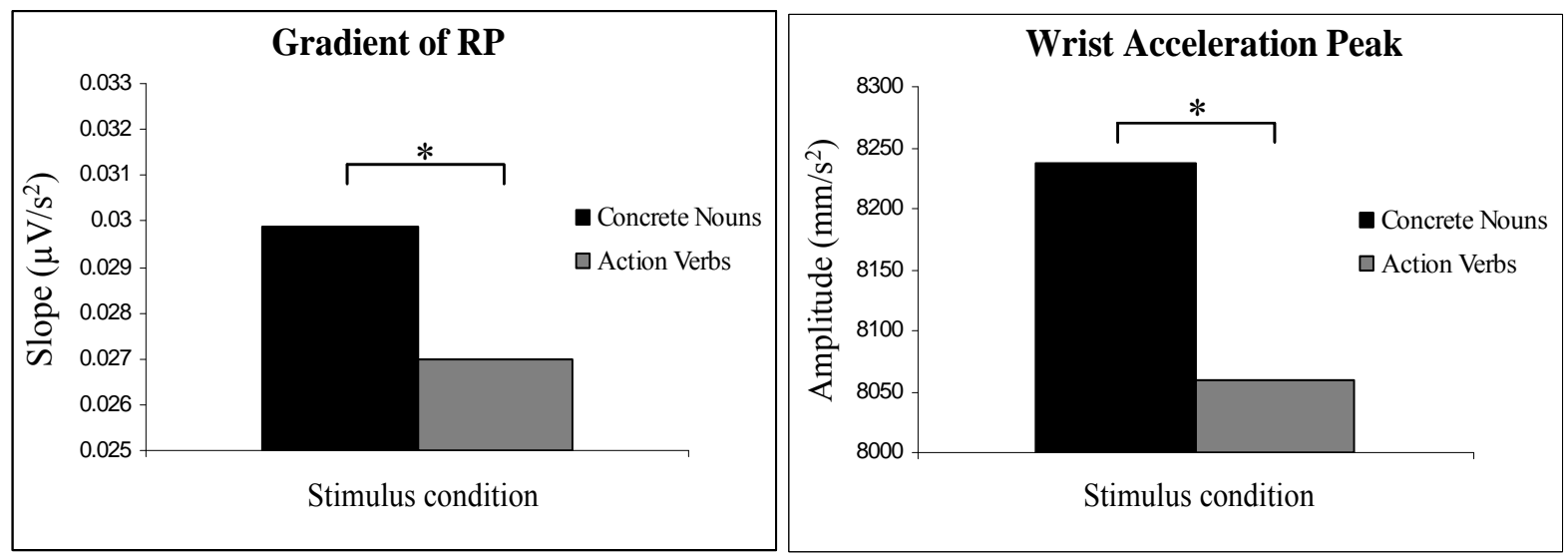